\title{
Pension behavior and policy
}

\author{
Philip W. S. Newall ${ }^{1}$ \\ Mike W. Peacey ${ }^{2}$
}

1 Experimental Gambling Research Laboratory, School of Health, Medical and Applied Sciences, CQUniversity, 120 Spencer St, Melbourne, VIC 3000, Australia

$2 \mathrm{NCH}$ at Northeastern, 19 Bedford Square, London, WC1B 3HH, United Kingdom

Cite as: Newall, P. W. S., \& Peacey, M. W. (2021). Pension behavior and policy. Journal of Behavioral and Experimental Finance. doi: 10.1016/j.jbef.2020.100449 
Abstract: Individuals benefit from smoothing consumption over time, a fact well illustrated in the domain of pension spending. But many potential benefits from consumption smoothing are lost in practice due to an overconsumption in the present and near-future compared to the far-future, which is known as "present bias". Present bias's impact on pensioner welfare could potentially be exacerbated by international trends toward greater pension freedoms. However, actual pension spending decisions can involve sudden transitions into bankruptcy, which are hard to reconcile even with behavioral hyperbolical discounting models that are traditionally used to explain present bias. We consider an intertemporal consumption problem from a time-consistent but bounded rationality perspective. In this limited foresight framework, an individual exponentially discounts utilities (at constant rate, $r$ ) for a finite amount of time (until S) but ignores utilities that occur beyond that (up to $T$ ). The consumption paths implied by this simple model involve sudden transitions into bankruptcy at time $S$, resembling observed patterns from an international dataset on pension spending. Furthermore, this perspective suggests that individuals could be helped to appropriately smooth consumption over time via policy interventions directed at extending their level of foresight.

\section{Highlights:}

- Limited foresight model is simple and requires minimal behavioral assumptions

- Resulting consumption paths display a sudden crash to zero

- Consumption under limited foresight leads to lower outcomes for the individual

- Policy focus on extending foresight, with limit case replicating full rationality

\section{Keywords:}

Time Preference; Impatience; Discounting; Myopia; Behavioral

\section{JEL codes:}

D15, D91. 


\section{Introduction}

With increasing life-spans, governments around the world are encouraging individuals to save more for retirement through a variety of pension schemes. Pension interventions can be traditional economic incentives such as pension tax breaks (Dilnot and Johnson, 1993), or behavioral "nudge" policies such as auto enrolment, aimed at simplifying the pension saving process (Thaler \& Benartzi, 2004; Choi et al, 2004; Curry, 2012). Much of the behavioral pensions debate thus far has therefore focused on the accumulation phase, where an individual saves into a 'pension pot' to provide them with a suitable income in retirement (Laibson et al 1998). This paper starts where that story ends: the subsequent problem of how retired individuals spend their accumulated savings.

Another current theme in regulatory changes is an increase in pension freedoms, giving individuals more options than ever before on how spend their pension savings (Keohane et al, 2015). For example, in the UK pension pots can now be spent however the individual wishes from the age of 55 onward, whereas retirees were previously required to purchase an annuity (GOV.UK, 2015). Following that policy change, tax receipts from pension withdrawals in 20156 were approximately $30 \%$ higher than predicted (OBR, 2015). Greater pension freedoms could exacerbate the existing policy problem of ensuring retirees achieve a sufficient level of retirement welfare, given established behavioral errors (Laibson, 1997).

People can be biased toward overconsumption when a large pot of money is on-hand. This can be illustrated via bankruptcy -- essentially the worst-case scenario for individual spending decisions. Looking at Florida lottery winners between 1993 and 2002, Hankins (2011) finds that winning \$50k - \$150k curiously does not reduce the chance of becoming bankrupt. Zagorsky (2013) finds that $18.7 \%$ of 72,000 US families between 1989 and 2007 who had received an inherence of $\$ 100,000$ or more had spent or lost all of it. Carlson et al. (2015) find that even NFL athletes, with median (and yet short-lived) earnings of $\$ 3.2$ million, spend money too quickly, with $15.7 \%$ filing for bankruptcy within 12 years of retiring.

Rationally, individuals should save and spend over the lifetime to produce a smooth level of consumption in each period (Friedman, 1957). This rational model does not accord with the pattern of results discussed so far, where individuals spend relatively too much in the present and near-future. Behavioral models of so-called "present bias" can do. Under hyperbolic discounting, for example, individuals also smooth their consumption over time, but spending it too high in the present than is in the individual's long-term interests (Laibson, 1997).

However, there are two limitations of the hyperbolic discounting perspective with respect to pension behavior and policy. First, although hyperbolic discounting leads to overspending, it does not directly predict instances of bankruptcy. Although this overspending will limit the late retirement budget, this budget should remain positive in all time periods. Second, hyperbolic discounting's main policy implication is that removing pensioners' freedom to spend from their accumulated pot may in fact lead to greater lifetime utility (Laibson, 1997). A different behavioral framework for present bias might be required to yield actionable policy insights in the current environment of high pension freedoms. 
Our framework considers these two issues surrounding the intertemporal consumption problem from a time-consistent but bounded rationality perspective (Jehiel \& Lilico, 2010). We show that under these conditions pension pot spending can either produce bankruptcy, or normative consumption smoothing, depending on an individual's level of foresight.

\section{Evidence on pension decumulation}

In response to pension flexibilities introduced in the UK, Keohane et al (2015) collected international evidence on decumulation paths of pensioners. Australia and USA were chosen because they have similar level of funded pension provision to the UK and have already deregulated their pensions regimes to increase pension freedoms. They conclude that pensioners are at risk of exhausting their pension pots early and note that will lead to lower outcomes for individuals, and an increased burden on the state.

In their analysis, three categories of individuals were characterized: First, a 'Cautious Australian', who has a $0.875 \%$ annual drawdown rate. This is based on the behavior of the average (mean) Australian drawdown rate. Second was, a 'Quick-spending Australian', who has an $11.6 \%$ annual drawdown rate. This is informed by Australian evidence estimating that $40 \%$ of the Australian population exhaust their pension pot by age 75. Finally, a 'Typical American', who has a drawdown rate of $8 \%$ was based on Americans' average pension withdrawal rate. Figure 1 (upper) presents the consumption paths for these three types, all of whom start with a $\$ 69,813$ pension pot (corresponding to a $70^{\text {th }}$-percentile man). In the first two cases the collapse of pension spending is most pronounced in the last two years before pension exhaustion.

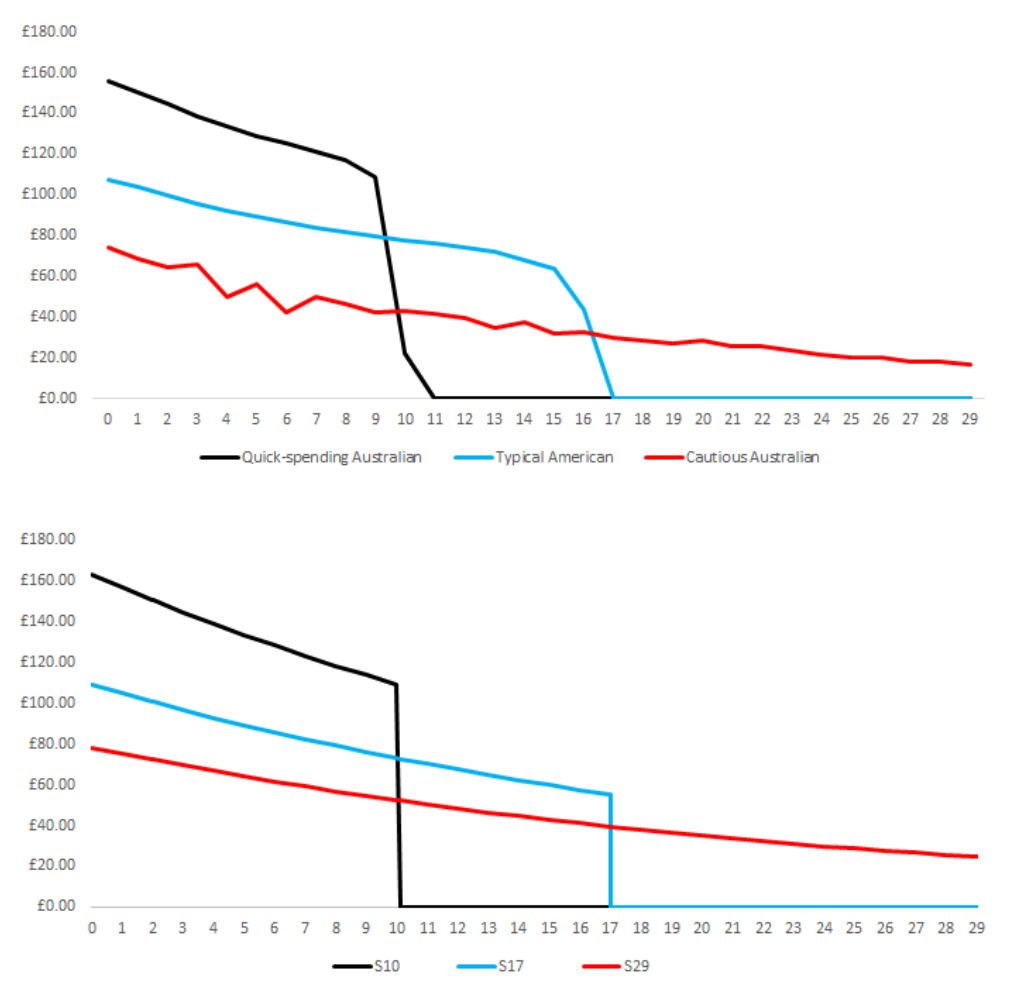

Figure 1: Comparison of data from Keohane et al. (2015)), p.36 (upper) with our Hamiltonian lifetime utility optimization model (lower). 


\section{Limited foresight Hamiltonian}

At the point of retirement, when she gains access to her endowment, an individual will have to make a choice over how she spends her pension savings. This class of problem is formulated and solved as a 'Hamiltonian' (Ross, 2015), and is common for problems such as natural resource allocation (Hartwick, 1990). The usual assumption of diminishing marginal utility results in a smoothing of consumption over time. At the same time, it is also usual to assume a positive discount rate which favors consumption now.

Consider an individual who is about to retire, who has built up pension savings $\omega$. Suppose the individual has some stable lifetime utility function $u(x)$, and stable lifetime exponential discount function, $e^{r t}$. Where $r$ is the usual 'discount rate', $r \in[0, \infty)$. During her retirement she therefore has flow utility $e^{-r t} u(x(t))$. Where $u^{\prime}(x(t))>0, u^{\prime \prime}(x(t))<0$.

If the individual understands that her pension saving must last her $T$ periods, then assuming $u(x(t))=\sqrt{x_{t}}$, solving the optimal control problem results in the following consumption function (Cretegny \& Rutherford 2004):

$$
c(t)=\frac{(i-r) \omega}{e^{(i-r) T}-1} e^{2(i-r) t}
$$

However if the individual has limited foresight, and so only considers spending over the next $S$ years (where $S<T$ ), the optimal control problem results in the following consumption function:

$$
c(t)=\left\{\begin{array}{cc}
\frac{(i-r) \omega}{e^{(i-r) S}-1} e^{2(i-r) t} & \text { if } \mathrm{t} \leq \mathrm{S} \\
0 & \text { if } \mathrm{t}>\mathrm{S}
\end{array}\right.
$$

Clearly, anyone who has $S<T$ suffers a distorted consumption path, where consumption is initially high but crashes to zero from $S$ onwards. The utility loss from optimizing for $S$ converges to zero as either $S \rightarrow T$; or, because infinitely impatient agents care only about the present, as $r \rightarrow \infty$. Thus each S-individual lives for the moment until suffering bankruptcy.

Figure 1 (lower) shows the resulting consumption paths for individuals with discount rates $r=0.02$, utility functions $u(x(t))=\sqrt{x_{t}}$, and three different values of $S(S=10,17$, and 29). The initial pension pot was assumed to be $\$ 69,813$, and weekly pension income is shown on the $y$-axis. The fit between our model predictions and the real-world data (Figure 1, upper) is close. 


\section{Policy and conclusion}

The current worldwide trend toward greater pension freedoms opens up new datasets on individual behavior to compare behavioral models against, but also magnifies the potential cost to individuals from behavioral errors. The pattern of results found by Keohane et al (2015). show that many pensioners exhaust their savings long before retirement, which is inconsistent with normative models (Friedman, 1957). However, these results also do not appear consistent with the hyperbolic discounting perspective on present bias. Although hyperbolic discounters will not achieve ex-post efficiency over the smoothing of their consumption, they do undertake some consumption smoothing. Any individual who exhausts all their savings is therefore not operating in this way, and two of the three spending profiles from Figure 1 (upper) show dramatic collapses in spending toward zero. Previous research has also shown that bankruptcy is not an isolated phenomena (Carlson et al., 2015; Hankins, 2011; Zagorsky, 2013).

We presented a simple model where overspending follows not from a change in the discount function (as in hyperbolic discounting), but from limiting the time horizon over which an exponential discount function is applied. This model was able to produce predictions in line with each of the three Keohane et al. (2015). empirical spending profiles, using time horizons of 10,17 , and 29 years, and standard assumptions of $r=0.02$, and a power utility function $(x(t))=\sqrt{x_{t}}$.

Beyond matters of empirical fit, the limited foresight approach does have one additional benefit with respect to policy (Jehiel \& Lilico 2010). Since present bias arises in hyperbolic discounting models due to a non-normative discount function, the general policy implication is to "pre-commit" individuals to a far-sighted plan which they then cannot change (Laibson, 1997). However, limited foresight models suggest that patient behavior could be enhanced by instead helping people to merely think more about the future, thereby expanding the planning horizon $(S)$ toward the objective time horizon $(T)$.

Some emerging experimental research has shown that patience can in fact be trained by thinking more about the future. Hershfield et al. (2011) tested the influence of age-progressed renderings of participants' faces on investment behavior. Participants exposed to ageprogressed renderings of their own face showed the highest levels of care for future financial outcomes. Alan and Ertac's (2018) randomized-controlled trial in Turkish schools, which aimed to help children imagine the future consequences of their actions, yielded significant increases in patience in incentivized tasks up to three years after program completion (Alan \& Ertac, 2018). 


\section{References}

1. Alan, Sule, and Seda Ertac. "Fostering patience in the classroom: Results from randomized educational intervention." Journal of Political Economy 126.5 (2018): 1865-1911.

2. Carlson, Kyle, et al. "Bankruptcy rates among NFL players with short-lived income spikes." American Economic Review 105.5 (2015): 381-84.

3. Choi, J. J., Laibson, D., Madrian, B. C., \& Metrick, A. (2004). For better or for worse: Default effects and 401 (k) savings behavior. In Perspectives on the Economics of Aging (pp. 81-126). University of Chicago Press.

4. Cretegny, L., and T. Rutherford. Worked examples in dynamic optimization: Analytic and Numeric models. mimeo. University of Colorado, 2004.

5. Curry, Chris. "The introduction of auto-enrolment and personal accounts to the UK in 2012." Pensions: An International Journal 13.4 (2008): 237-245.

6. Dilnot, Andrew, and Paul Johnson. The taxation of private pensions. No. R43. IFS Reports, Institute for Fiscal Studies, 1993.

7. Friedman, Milton. "A Theory of the Consumption Function." NBER Books (1957).

8. GOV.UK. (2015). Pension changes 2015. [online] Available at: https://www.gov.uk/government/news/pension-changes-2015 [Accessed 31 Jul. 2019].

9. Hankins, Scott, Mark Hoekstra, and Paige Marta Skiba. "The ticket to easy street? The financial consequences of winning the lottery." Review of Economics and Statistics 93.3 (2011): 961-969.

10. Hartwick, J. M. (1990). Natural resources, national accounting and economic depreciation. Journal of public Economics, 43(3):291\{304.

11. Hershfield, H. E., Goldstein, D. G., Sharpe, W. F., Fox, J., Yeykelis, L., Carstensen, L. L., \& Bailenson, J. N. (2011). Increasing saving behavior through age-progressed renderings of the future self. Journal of Marketing Research, 48(SPL), S23-S37.

12. Jehiel, P., \& Lilico, A. (2010). Smoking today and stopping tomorrow: A limited foresight perspective. CESifo Economic Studies, 56(2), 141-164.

13. Keohane, N., Evans, K., and Richards, B. (2015). Golden years? What freedom and choice will mean for uk pensioners. Social Market Foundation.

14. Laibson, David I., et al. "Self-control and saving for retirement." Brookings papers on economic activity 1998.1 (1998): 91-196.

15. OBR, "Office for Budget Responsibility Economic and Fiscal Outlook Nov 2015". Vol. 8573. The Stationery Office, 2015.

16. Ross, I. M. (2015). A primer on pontryagin's principle in optimal control (2nd ed.). New York: Collegiate Publishers.

17. Thaler, R. H., \& Benartzi, S. (2004). Save more tomorrow ${ }^{\text {TM }}$ : Using behavioral economics to increase employee saving. Journal of political Economy, 112(S1), S164-S187.

18. Zagorsky, Jay L. "Do people save or spend their inheritances? Understanding what happens to inherited wealth." Journal of Family and Economic Issues 34.1 (2013): 6476. 